\title{
0-GlcNAcylation of AMPA Receptor GluA2 Is Associated with a Novel Form of Long-Term Depression at Hippocampal Synapses
}

\author{
Erica W. Taylor, ${ }^{1 \star}$ Kai Wang, ${ }^{1 *}$ Amy R. Nelson, ${ }^{\dagger \dagger}$ Teruko M. Bredemann, ${ }^{1 \dagger}$ Kyle B. Fraser, ${ }^{2}$ Sarah M. Clinton, ${ }^{3}$ \\ Rosemary Puckett, ${ }^{1}$ Richard B. Marchase, ${ }^{1}$ John C. Chatham, ${ }^{4 \neq}$ and Lori L. McMahon ${ }^{1{ }^{\ddagger}}$ \\ ${ }^{1}$ Department of Cell, Developmental and Integrative Biology, ${ }^{2}$ Department of Neurology, ${ }^{3}$ Department of Psychiatry and Behavioral Neurobiology, and \\ ${ }^{4}$ Division of Molecular and Cellular Pathology, Department of Pathology, University of Alabama at Birmingham, Birmingham, Alabama 35294
}

\begin{abstract}
Serine phosphorylation of AMPA receptor (AMPAR) subunits GluA1 and GluA2 modulates AMPAR trafficking during long-term changes in strength of hippocampal excitatory transmission required for normal learning and memory. The post-translational addition and removal of 0 -linked $\beta$ - $N$-acetylglucosamine $(0-\mathrm{GlcNAc})$ also occurs on serine residues. This, together with the high expression of the enzymes 0-GlcNAc transferase (OGT) and $\beta$ - $N$-acetylglucosamindase (O-GlcNAcase), suggests a potential role for O-GlcNAcylation in modifying synaptic efficacy and cognition. Furthermore, because key synaptic proteins are 0-GlcNAcylated, this modification may be as important to brain function as phosphorylation, yet its physiological significance remains unknown. We report that acutely increasing 0-GlcNAcylation in Sprague Dawley rat hippocampal slices induces an NMDA receptor and protein kinase C-independent long-term depression (LTD) at hippocampal CA3-CA1 synapses (0-GcNAc LTD). This LTD requires AMPAR GluA2 subunits, which we demonstrate are 0-GlcNAcylated. Increasing 0-GlcNAcylation interferes with long-term potentiation, and in hippocampal behavioral assays, it prevents novel object recognition and placement without affecting contextual fear conditioning. Our findings provide evidence that O-GlcNAcylation dynamically modulates hippocampal synaptic function and learning and memory, and suggest that altered 0-GlcNAc levels could underlie cognitive dysfunction in neurological diseases.
\end{abstract}

Key words: depression; hippocampus; LTD; LTP; O-GlcNAc; synaptic transmission

\section{Introduction}

During expression of NMDA receptor (NMDAR) -dependent long-term potentiation (LTP) and long-term depression (LTD) at hippocampal synapses, trafficking of AMPA receptors (AMPARs) into and out of the postsynaptic density is critically dependent upon phosphorylation and dephosphorylation of key serine residues on GluA1 and GluA2 subunits (Lee et al., 2000; Malinow and Malenka, 2002; Lee et al., 2003). Serine (or threonine) residues can also be modified by O-linked attachment of $\beta$ - $N$-acetylglucosamine (O-GlcNAc), an atypical glycosylation

Received Oct. 8, 2012; revised Nov. 4, 2013; accepted Nov. 6, 2013.

Author contributions: E.W.T., K.W., R.B.M., J.C.C., and L.L.M. designed research; E.W.T., K.W., A.R.N., T.M.B., K.B.F., and R.P. performed research; E.W.T., K.W., A.R.N., T.M.B., K.B.F., S.M.C., and R.P. analyzed data; E.W.T., K.W., J.C.C., and L.L.M. wrote the paper.

Research was supported by National Institutes of Health grants F31DK084798 to E.W.T., R21NS063359 and R01NS076312 to J.C.C. and L.L.M., and P30NS47466 to J. Hablitz. We thank Dr. Thomas Van Groen, Director of the University of Alabama at Birmingham Behavioral Assessment Core for his assistance with our behavioral assays and Ramsha Farrukh and Kevin Yang for their technical assistance with the immunohistochemistry.

*E.W.T. and K.W. contributed equally to this work.

${ }^{\dagger}$ A.R.N. and T.M.B. contributed equally to this work.

‡J.C.C. and L.L.M. contributed equally to this work.

The authors declare no competing financial interests.

Correspondence should be addressed to Dr. Lori L. McMahon, University of Alabama at Birmingham, Department

of Cell, Developmental, and Integrative Biology, 1918 University Boulevard, MCLM964, Birmingham, AL 35294. E-mail:mcmahon@uab.edu.

DOI:10.1523/JNEUROSCI.4761-12.2014

Copyright $\odot 2014$ the authors $\quad 0270-6474 / 14 / 340010-12 \$ 15.00 / 0$ first identified in 1984, which is added to proteins by O-GlcNAc transferase (OGT) and removed by O-GlcNAcase (Torres and Hart, 1984). O-GlcNAcylation is increasingly recognized as a ubiquitous, tightly regulated post-translational modification analogous to phosphorylation. Both OGT and O-GlcNAcase are abundant in hippocampal synaptosomes, and O-GlcNAcase is found near synaptic vesicles in presynaptic terminals and around microtubules in dendrites (Cole and Hart, 2001; Akimoto et al., 2003). Furthermore, several presynaptic and postsynaptic proteins, including synapsin, piccolo; bassoon; and neurofilaments L, H, and $\mathrm{M}$ are O-GlcNAc modified (Khidekel et al., 2003, 2004, 2007), although the functional significance is unknown. Despite these observations, our understanding of the physiological role of O-GlcNAcylation in modulating brain function remains remarkably limited. To date, only a handful of studies exist examining $\mathrm{O}-$ GlcNAcylation in the nervous system, with most focusing on the relationship between decreased O-GlcNAcylation and hyperphosphorylation of tau in Alzheimer's disease (AD; Yuzwa et al., 2008; Deng et al., 2009; Yuzwa and Vocadlo, 2009). Because synaptic efficacy is highly regulated by serine/threonine phosphorylation/dephosphorylation of synaptic proteins (Malenka and Bear, 2004), it is possible that O-GlcNAcylation, which also occurs on serine/threonine residues, is as important as phosphorylation in modulating synaptic function. The expression patterns of OGT and O-GlcNAcase in hippocampus suggest hippocampal 
synaptic activity and hippocampal-dependent learning and memory may be regulated by O-GlcNAcylation of synaptic proteins. Indeed, two recent studies investigated the impact of increasing or decreasing (Kanno et al., 2010) O-GlcNAc levels on LTP at hippocampal CA3-CA1 synapses. Unfortunately, the studies reported contradictory results and, importantly, neither study investigated effects of acute modulation of O-GlcNAc levels on synaptic processes underlying memory formation.

Here, we investigated the impact of acutely increasing O-GlcNAcylation on basal glutamate transmission at CA3-CA1 synapses, expression of NMDAR-dependent LTP and LTD, and hippocampal-dependent learning. We find that increased $\mathrm{O}-$ GlcNAcylation induces a novel NMDAR- and protein kinase $\mathrm{C}$ (PKC)-independent form of long-lasting synaptic depression at CA3-CA1 synapses, which require GluA2 AMPAR subunits, which undergo O-GlcNAc modification. We also find that increasing O-GlcNAcylation interferes with LTP and impairs novel object recognition and placement, without affecting contextual fear conditioning (CFC). In summary, we report a novel LTD at hippocampal synapses linked with O-GlcNAc modification of the GluA2 AMPAR subunit and that globally increasing O-GlcNAc modification in vivo throughout brain alters some forms of hippocampal-dependent learning and memory.

\section{Materials and Methods}

All experiments were conducted with an approved protocol from the University of Alabama at Birmingham Institutional Animal Care and Use Committee. All procedures are in compliance with guidelines put forth by the National Institutes of Health.

\section{Immunohistochemistry}

Rats. Six- to eight-week-old male Sprague Dawley rats were intraperitoneally injected with vehicle (saline) or thiamet-G and $8 \mathrm{~h}$ or $24 \mathrm{~h}$ later were transcardially perfused with PBS followed by $4 \%$ paraformaldehyde. One hemisphere was sectioned coronally and the other sagittally on a vibratome at $50 \mu \mathrm{m}$ in six series. A series of tissue was washed and incubated in blocking buffer (10\% normal donkey serum, $0.3 \%$ Triton, PBS) for $90 \mathrm{~min}$. Primary antibody in blocking buffer was applied overnight at $4^{\circ} \mathrm{C}$ at the following concentrations: $\alpha$-O-GlcNAc CTD 110.6 (1:100, mouse), glial fibrillary acidic protein (GFAP; $1: 500$, goat), and glutamic acid decarboxylase 67 (GAD-67; 1:500, rabbit). After washing, $2^{\circ}$ antibody in blocking buffer was applied in the dark for $90 \mathrm{~min}$ at room temperature at the following concentrations: $\alpha$-rabbit IgG Alexa Fluor 647 (1:250), $\alpha$-mouse IgM Alexa Fluor 488 (1:500), $\alpha$-goat IgG Alexa Fluor 555 (1:500). A negative control with no $1^{\circ}$ antibody confirmed the absence of nonspecific binding of $2^{\circ}$ antibodies. All tissue was treated with Hoechst nuclear stain for $10 \mathrm{~min}$, washed, and mounted. Sagittal sections were imaged in entirety at $10 \times$ on an Olympus BX63 motorized microscope. Area CA1 of each coronal section was imaged at $40 \times$ on a Zeiss Axioplan 2 fluorescent microscope and mean fluorescence intensity was quantified for each image using ImageJ. High-resolution confocal images of coronal sections shown in the Figure $7, B-D$, was acquired on a Leica TCS SP8 at $40 \times$.

Human. Human hippocampus was acquired from the Joseph and Kathleen Bryan Alzheimer's Disease Research Center at Duke University and experiments were conducted with permission from the University of Alabama at Birmingham Institutional Review Board for Human Use (Hulette et al., 1997). Hippocampal sections from an 85-year-old male subject with no cognitive impairment and postmortem interval of $5.67 \mathrm{~h}$ were used for this experiment. Sections were pressure cooked for $30 \mathrm{~min}$ in $10 \mathrm{~mm}$ citrate buffer, $\mathrm{pH}$ 6.0. Tissue was then washed and treated with hydrogen peroxide for $10 \mathrm{~min}$. Following $90 \mathrm{~min}$ in blocking buffer, floating sections were incubated with $\alpha$-O-GlcNAc (1:100, mouse) overnight at $4^{\circ} \mathrm{C}$. The next day, tissue was washed and then incubated with ImmPRESS anti-mouse Ig (Vector) for $90 \mathrm{~min}$ followed by washing and 30 min treatment with Vectastain ABC (Vector Laboratories). Finally, tissue was washed and then incubated in ImmPACT NovaRED (Vector
Laboratories) for $6 \mathrm{~min}$. Sections were permanently mounted and imaged at $20 \times$ on an Olympus BX51 microscope.

\section{Increasing protein O-GlcNAcylation}

Protein O-GlcNAcylation was increased by a $10 \mathrm{~min}$ exposure of hippocampal slices $(400 \mu \mathrm{m})$ from 3 - to 4 -week-old male and female rats to glucosamine, PUGNAc, or thiamet-G. In in vivo behavioral studies, thiamet-G (dissolved in saline) was injected intraperitoneally at 10 $\mathrm{mg} / \mathrm{kg}$ (6- to 8-week-old male rats) and experiments were performed 2 and $4 \mathrm{~h}$ postinjection. Rats were killed at $8 \mathrm{~h}$ post injection at the conclusion of the behavioral experiments.

\section{Immunoblot and immunoprecipitation}

Protein concentration was determined using a colorimetric protein assay (Bio-Rad Laboratories). CA1 homogenates containing $35 \mu \mathrm{g}$ protein were separated on $7.5 \%$ SDS-PAGE and transferred overnight to polyvinylidene difluoride membrane. Membranes were incubated with primary antibodies as specified in each experiment at $4^{\circ} \mathrm{C}$ overnight. After 3 washes with TBST/PBS, membranes were incubated with appropriate secondary antibodies for $1 \mathrm{~h}$ at room temperature, followed by three TBST/PBS washes. The blots were visualized with enhanced chemiluminescence (PerkinElmer). For immunoprecipitation, hippocampal homogenates were incubated with $\alpha$-GluA2 antibody together with Protein A/G plus-agarose (Santa Cruz Biotechnology) at $4^{\circ} \mathrm{C}$ overnight. Precipitates were washed five times with cold PBS buffer, and resolved by SDSPAGE. O-GlcNAcylation and tubulin levels were quantified by densitometric scanning using ImageJ, and $\mathrm{O}$-GlcNAcylation values were normalized to tubulin. O-GlcNAcylation was visualized using anti-OGlcNAc antibody CTD 110.6 and its specificity has been well documented (Zou et al., 2012).

\section{Synaptosome fractionation}

Hippocampal samples were homogenized using ice-cold TEVP buffer ( $10 \mathrm{~mm}$ Tris base, $5 \mathrm{~mm} \mathrm{NaF}, 1 \mathrm{~mm}$ Na3VO4, 1 mm EDTA, 1 mm EGTA $2.5 \%$ protease inhibitor cocktail), $\mathrm{pH} 7.4$, containing $320 \mathrm{~mm}$ sucrose, on wet ice. The homogenate was centrifuged at $800 \times g$ for $10 \mathrm{~min}$ at $4^{\circ} \mathrm{C}$ and the resulting supernatant removed and centrifuged at $9200 \times g$ for 15 min. The supernatant was collected (cytosol fraction); the pellet (crude synaptosomal membrane) from the second centrifugation was resuspended in TEVP buffer and sonicated on wet ice. Samples were subjected to Western blot analysis as indicated above.

\section{Hippocampal slice preparation and electrophysiology}

Preparation of hippocampal slices $(400 \mu \mathrm{m})$ from 3- to 4-week-old male and female Sprague Dawley rats and extracellular dendritic field EPSP (fEPSPs) recordings from CA3-CA1 synapses (Axoclamp 2B; Molecular Devices) followed previously published methods (Smith and McMahon, 2005; McCutchen et al., 2006; Scheiderer et al., 2008).

LTP induction. The high-frequency stimulation (HFS) protocol used to induce NMDAR-dependent LTP consisted of four $0.5 \mathrm{~s}$ trains of 100 $\mathrm{Hz}$ stimuli separated by $20 \mathrm{~s}$ (Smith and McMahon, 2005, 2006).

LTD induction. NMDAR-dependent LTD was induced using lowfrequency stimulation (LFS; $1 \mathrm{~Hz}, 15 \mathrm{~min}$; Dudek and Bear, 1992). Software written in LabVIEW (National Instruments) was used for data collection and analysis. Data were filtered at $2 \mathrm{kHz}$. The initial slope of the fEPSP was measured and plotted versus time, with each point representing the average of five consecutive data points.

\section{AMPAR GluA2 mutant mice}

Electrophysiology and Western blot analysis were done using hippocampal slices prepared as described above from 2- to 6-month-old male B6.129-Gria2 ${ }^{\mathrm{tm} 1 \text { Rod }} / \mathrm{J}$ mutant mice purchased from The Jackson Laboratory. Genotyping was done with PCR ( primer sequences-wildtype-5'GGTTGGTCACTCACCTGCTT3', common-5'TCGCCCATTTTCCCATATAC3', mutant- 5'GCCTGAAGAACGAGATCAGC3' $^{\prime}$ ). In some cases, immunoblot analysis was also performed to confirm the presence or absence of GluA2.

\section{Behavior}

All behavioral assessments were performed in 6- to 8-week-old male rats and were video recorded and hand scored by at least two experimenters 
blinded to treatment group. For open field, EthoVision Noldus rodent behavior software was used for further analysis. Rats were acclimated to each behavior room for at least 40 min before assessment protocols.

\section{Novel object and placement recognition} In each of these tasks, rats were handled for 1 min then placed in a $40 \times 40 \times 60 \mathrm{~cm}(1 \times \mathrm{w} \times$ h) black Plexiglas box for $10 \mathrm{~min}$ to acclimate to the environment. The next day animals were placed in the same box $2 \mathrm{~h}$ post-thiamet-G/ vehicle treatment with two identical objects for $3 \mathrm{~min}$ then returned to their cages. After a $2 \mathrm{~h}$ interval, the animals were returned to the box for a $3 \mathrm{~min}$ exposure to one familiar object and one new (novel) object in the novel object recognition (NOR) task or were exposed to the same two objects from training but one object was placed in a new location in the novel object placement (NOP) task. All training and testing sessions were analyzed for exploratory behaviors related to both the novel and familiar objects for NOR or the familiar and novel location for NOP. Exploratory behaviors consist of the rat's nose coming in direct contact or within $1 \mathrm{~cm}$ of the object. Animals were excluded if they did not have at least $5 \mathrm{~s}$ of exploratory behavior or $1 \mathrm{~s}$ total exploration of each object. Experimenters were blind to the experimental condition during analysis.

\section{Open field testing}

Assays were performed as previously described (Stead et al., 2006). Total distance traveled, latency to enter the center of the open field, amount of time spent in the center $(80 \times 80 \mathrm{~cm})$, periphery $(10 \mathrm{~cm})$, and corners of the apparatus were analyzed. Open field testing was conducted at both 2 and $4 \mathrm{~h}$ post-thiamet-G/vehicle injection.

\section{Contextual fear conditioning}

Assays were performed as previously described (Gupta et al., 2010). Rats were placed in a test box for $9 \mathrm{~min}$. This consisted of $2 \mathrm{~min}$ habituation followed by a $7 \mathrm{~min}$ training period, which included three footshocks ( 1 s, $0.50 \mathrm{~mA}$ ) delivered at $2 \mathrm{~min}$ intervals and concluded with $1 \mathrm{~min}$ of additional exploration time. Rats were returned to the test box $24 \mathrm{~h}$ later for $5 \mathrm{~min}$ and the amount of time spent freezing was measured. CFC training was performed $2 \mathrm{~h}$ post-thiamet-G/vehicle treatment. Animals were excluded if they did not have at least $8 \%$ freezing, which is equal to the average freezing in the nonshock controls.

\section{Statistics}

All data are presented as mean \pm SEM. Only experiments with $<5 \%$ change in the original baseline were included in the analysis. The magnitude of the LTD and LTP was measured at 35 min following HFS, LFS, or glucosamine, PUGNAc, and thiamet-G washout. Statistical analysis of electrophysiology data was performed with Student's $t$ test or one-way ANOVA when appropriate. Statistical analysis of behavioral data was performed with one-way and one-way repeated-measures ANOVA with Tukey's post hoc analysis when appropriate. Only one slice in each experimental condition per animal was included in the electrophysiology datasets, so the $n$ number reflects both the slice and animal number. Significant differences were determined at $p<0.05$.

\section{Chemicals}

Immunoblot and immunohistochemistry. Chemicals include: T-PER (Pierce), OGT (Sigma-Aldrich), $\alpha$-NCOAT (L-14; O-GlcNAcase; Santa Cruz Biotechnology), $\alpha$-GluA2 (Millipore), $\alpha$-O-GlcNAc antibody CTD 110.6 (kind gift from Mary Ann Accavitti, University of Alabama at Birmingham Epitope Recognition and Immunodetection Facility), $\alpha$-GFAP (Abcam),
$\alpha$-GAD (Novus), Alexa Fluor IgG secondaries (Invitrogen), and Alexa Fluor IgM secondary (Jackson ImmunoResearch).

Electrophysiology. Chemicals include: D $(+)$ glucosamine hydrochloride (Sigma-Aldrich), PUGNAc (Toronto Research Chemicals), thiamet-G (SD ChemMolecules), DL-2-amino-5-phosphonopentanoic acid (Sigma-Aldrich), picrotoxin (Sigma-Aldrich), and bisindolylmaleimide I (Tocris Bioscience).

\section{Results}

\section{O-GlcNAcylated proteins are highly expressed}

\section{throughout brain}

Limited information is available regarding the distribution of O-GlcNAcylated proteins throughout rat brain (Fig. 1). Using immunohistochemistry, we find that O-GlcNAcylated proteins are ubiquitously expressed, and are enriched in hippocampus with dense localization to CA1 pyramidal cells (Fig. $2 A)$. Double immunofluorescence staining confirms that O-GlcNAcylated proteins are also present in astrocytes (antiGFAP) and GABAergic interneurons (anti-GAD-67; Fig. 2D1,D2). Importantly, O-GlcNAcylated proteins were also found in human hippocampus with a similar distribution to that seen in rat hippocampus. O-GlcNAcylated proteins are enriched in CA1 pyramidal cells (Fig. 2E1,E2), as well as other neuronal cells that are likely GABAergic interneurons and astrocytes.

Following in vivo treatment with the O-GlcNAcase inhibitor thiamet-G (TMG), O-GlcNAc levels are elevated $8 \mathrm{~h}$ (Vehicle: $99.64 \pm 6$, TMG: $158.33 \pm 11 ; p<0.001)$ and $24 \mathrm{~h}$ (Vehicle: 85.09 \pm 4 , TMG: $131.96 \pm 15 ; p<0.05)$ post injection (Fig. $2 B$ ). Thiamet-G treatment increased mean O-GlcNAc fluorescence staining intensity throughout brain, including hippocampus (Fig. 2A-C). No identifiable fluorescent signal other than autofluorescence in blood vessels was observed when primary antibodies were omitted (data not shown), demonstrating specificity. 
A

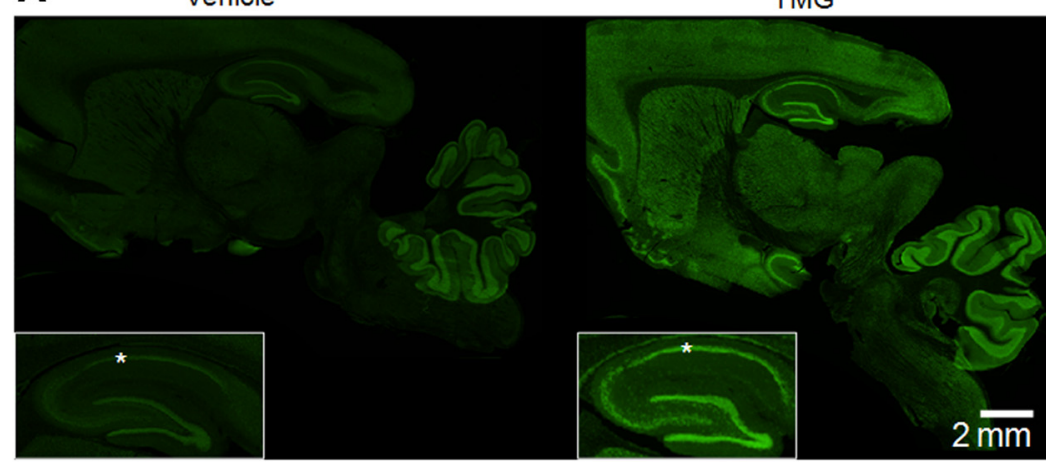

B Vehicle
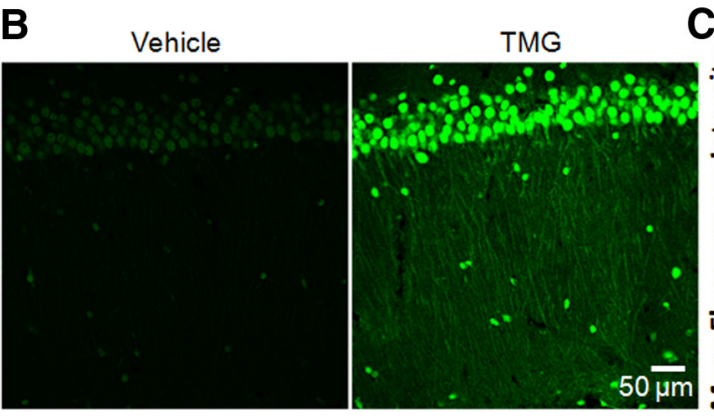

$C^{250}$ Vehicle

$50 \mu \mathrm{m}$



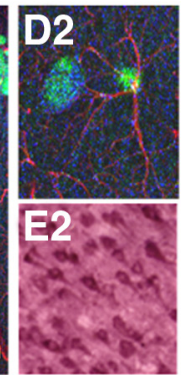

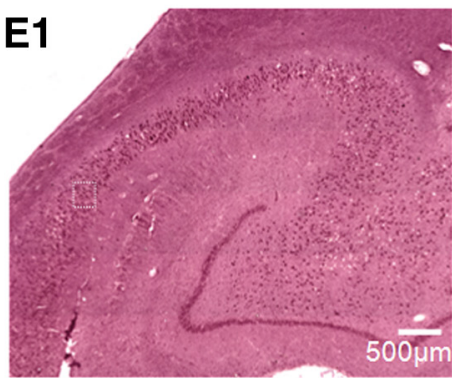

$8 \mathrm{Hr}$

Figure 2. Protein 0-GICNAcylation is ubiquitous and is increased by in vivo thiamet-G-treatment. $A, 0$-GIcNAc staining (green) in sagittal brain sections from Vehicle- and TMG-injected $(10 \mathrm{mg} / \mathrm{kg})$ rats $8 \mathrm{~h}$ post injection including hippocampal formation (inset) and area CA1 (asterisks; $10 \times$ magnification). B, 0 -GlcNAcylated proteins are increased in area CA1 of rat hippocampus $8 \mathrm{~h}$ post TMG injection (40 $\times$ magnification). C, Quantification of mean fluorescence intensity in area CA1 from Vehicle- and TMGtreated rats, $8 \mathrm{~h}$ (Vehicle: $n=5$, TMG: $n=7$ ) and $24 \mathrm{~h}$ (Vehicle: $n=4$, TMG: $n=3$ ) post intraperitoneal injection. D1, 0 -GIcNAcylated proteins (green) are located in CA1 pyramidal cells, inhibitory interneurons (blue), and astrocytes (red; $40 \times$ magnification). D2, Boxed area in D1 showing an 0-GICNAC-positive astrocyte and inhibitory interneuron. E1, 0-GICNAcylated proteins detected in human hippocampus (20X magnification). E2, Boxed area in E1 showing 0-GIcNAc-positive CA1 pyramidal cells. ${ }^{*} p<0.05$ and ${ }^{* *} p<0.001$. Error bars indicate SEM.

Application of the HBP substrate glucosamine or pharmacological inhibitors of $\mathrm{O}$-GlcNAcase increases protein $\mathrm{O}-\mathrm{GlcNAc}$ levels in acute hippocampal slices

To determine whether protein O-GlcNAc levels can be dynamically modulated in acute hippocampal slices, we first applied glucosamine for $10 \mathrm{~min}$ at $5 \mathrm{~mm}$, a concentration typically used in studies of other organ systems to increase protein O-GlcNAc levels (Han and Kudlow, 1997; Kneass and Marchase, 2004; Liu et al., 2006; Fülöp et al., 2007). Immunoblot analysis of isolated CA1 regions from glucosamine-treated slices demonstrated that protein O-GlcNAc levels were significantly increased compared with vehicle-treated slices (Fig. 3A1,A2). We next treated slices with $100 \mu \mathrm{M}$ glucosamine and observed an increase comparable to the $5 \mathrm{~mm}$ treatment (Fig. $3 A 1, A 2$ ), consistent with earlier studies demonstrating that micromolar concentrations of glucosamine can increase O-GlcNAc levels (Laczy et al., 2011). Finally, we also confirmed that glucosamine treatment increases protein $\mathrm{O}-\mathrm{GlcNAc}$ levels in hippocampal synaptosomes ( $p<0.05$; Fig. 3B1,B2).

We reasoned that if OGT, the enzyme that adds O-GlcNAc to serine/threonine residues, is tonically active in acute hippocampal slices, then pharmacologically blocking O-GlcNAcase, the enzyme that removes O-GlcNAc moieties, should also increase protein O-GlcNAc levels. To test this, slices were treated for $10 \mathrm{~min}$ with two different O-GlcNAcase inhibitors, PUGNAc $(30 \mu \mathrm{M})$ and thiamet-G $(1 \mu \mathrm{M})$, and both were found to significantly increase protein O-GlcNAc levels in area CA1. The increase in protein O-GlcNAc levels observed following application of either substrate or O-GlcNAcase inhibitors was of the same magnitude (one-way ANOVA; $F_{(3,12)}=3.79, p<0.05$; Fig. $3 A 1, A 2)$.

In time course studies, the glucosamineinduced increase in O-GlcNAcylation is transient, returning to baseline by $20 \mathrm{~min}$ post treatment $(p<0.05$; Fig. $3 C 1, C 2)$. The thiamet-G-induced increase in O-GlcNAcylation remained significantly elevated up to $120 \mathrm{~min}$ after treatment, the longest time point we assayed $(p<$ 0.05 ; Fig. $3 D 1, D 2)$, indicating that pharmacological inhibition of O-GlcNAcase is long lasting.

Acutely increasing protein $\mathrm{O}$ -

GlcNAcylation induces a novel form of LTD at CA3-CA1 synapses

To investigate the effect of acutely increasing protein O-GlcNAcylation on basal glutamatergic transmission at hippocampal CA3 CA1 synapses, we recorded extracellular dendritic field potentials in slices and bathapplied glucosamine ( $5 \mathrm{~mm}$ for $10 \mathrm{~min}$ ). We observed a significant synaptic depression that lasted the duration of the recording (85 $\pm 3 \%$ of baseline fEPSP slope; $p<$ 0.0001; Fig. $4 A$ ), up to $60 \mathrm{~min}$. As in the immunoblot experiments, we also investigated whether the lower glucosamine concentration $(100 \mu \mathrm{M})$ would induce similar synaptic depression. Indeed, a $10 \mathrm{~min}$ bath application of $100 \mu \mathrm{M}$ glucosamine induced synaptic depression with a similar magnitude as $5 \mathrm{~mm}$ glucosamine ( $86 \pm 3 \%$ of baseline fEPSP slope; $p<0.001$; Fig. $4 B$ ).

We reasoned that if this synaptic depression is a result of increased O-GlcNAcylation, then pharmacologically blocking O-GlcNAcase, should also depress transmission. Indeed, the O-GlcNAcase inhibitors, PUGNAc ( $30 \mu \mathrm{M}, 84 \pm 4 \%$ of baseline fEPSP slope; $p<0.001)$ and thiamet-G $(1 \mu \mathrm{M}, 81 \pm 4 \%$ of baseline fEPSP slope; $p<0.001)$ induced a stable long-lasting synaptic depression (Fig. $4 C, D$ ) of the same magnitude as $100 \mu \mathrm{M}$ or $5 \mathrm{~mm}$ glucosamine (one-way ANOVA; $F_{(3,28)}=2.95, p>0.05$; Fig. 4). Collectively these data strongly suggest that increasing protein $\mathrm{O}-\mathrm{GlcNAcylation}$, either by increasing synthesis with glucosamine, or by preventing removal of O-GlcNAc by inhibit- 

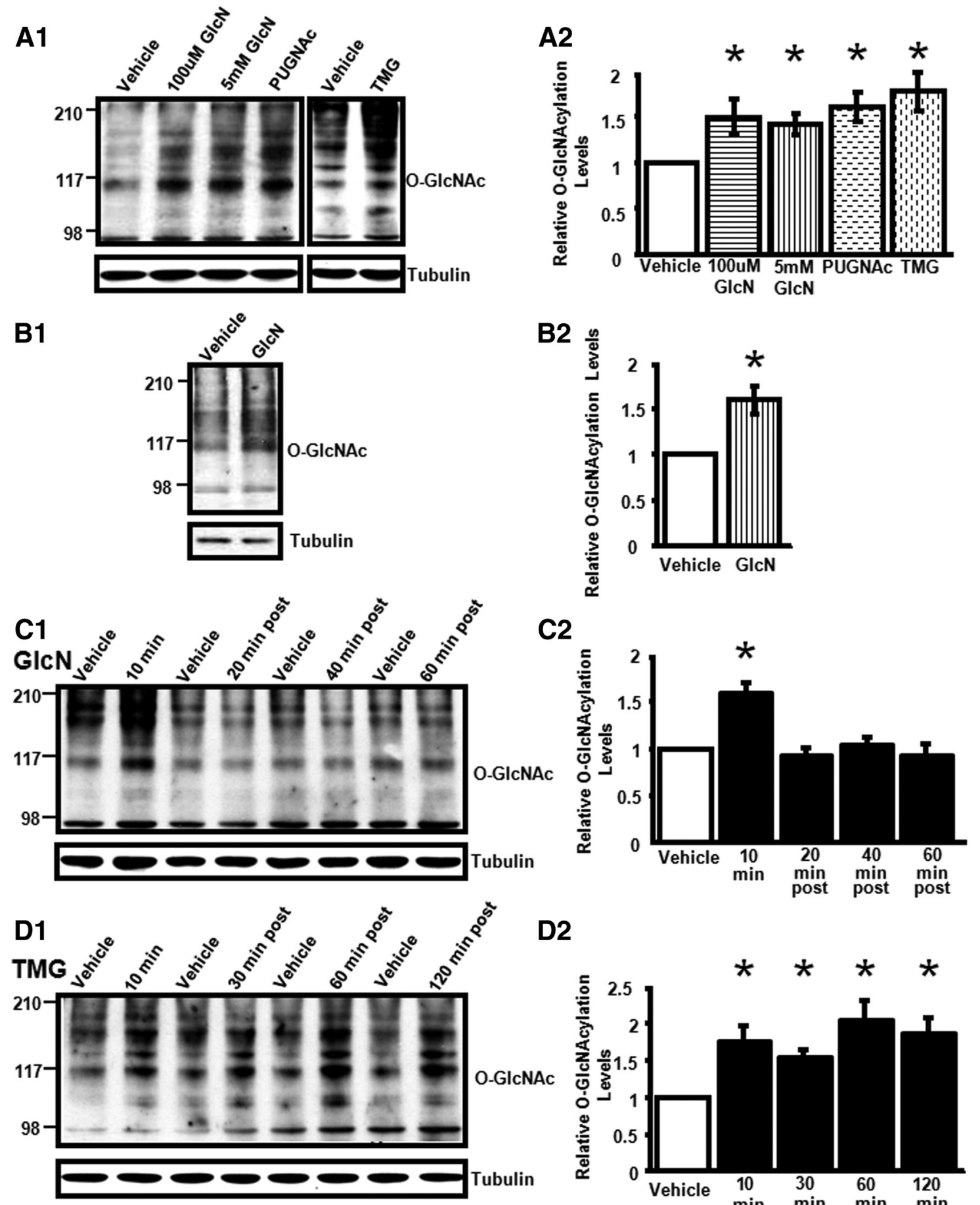

D2



Figure 3. Glucosamine, PUGNAc, and thiamet-G increase protein 0 -GIcNAcylation in rat hippocampus. A1, $A 2$, GIcN (100 and $5 \mathrm{~mm}), \operatorname{PUGNAc}(30 \mu \mathrm{M})$, or TMG (1 $\mu \mathrm{M})$ application to acute slices

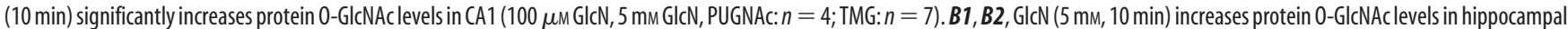
synaptosomes $(n=3)$. C1, C2, GlCN (5 mM, $10 \mathrm{~min})$ increases 0 -GlcNAcylation in CA1 that returns to baseline by 20 min post treatment $(n=12) . \mathbf{D 1}, \mathbf{D 2}$, TMG $(1 \mu \mathrm{M}, 10 \mathrm{~min})$ induces a prolonged increase in 0-GlcNAcylation, up to 120 min post treatment $(n=10)$. C, $D$, Each treatment time point compared with time-matched Vehicle control. ${ }^{*} p<0.05$. Error bars indicate SEM.

ing O-GlcNAcase, induces long-lasting synaptic depression. Thus, we have termed this novel plasticity, O-GlcNAc LTD. Finally, this novel synaptic depression is saturable because no significant depression was induced following the fourth round of glucosamine application $(68 \pm 4 \%$ of baseline fEPSP slope following fourth application vs $64 \pm 6 \%$ of baseline fEPSP slope after fifth application; $p>0.05$; Fig. $4 E$ ). This observation is important, as other forms of long-term plasticity at CA3-CA1 synapses implicated in learning and memory also reach saturation following repeated rounds of induction (Bliss and Lomo, 1973; Dudek and Bear, 1992). Furthermore, the saturability of $\mathrm{O}-$ GlcNAc LTD is consistent with this being a physiological rather than a pathological effect of an increase in protein O-GlcNAcylation. 

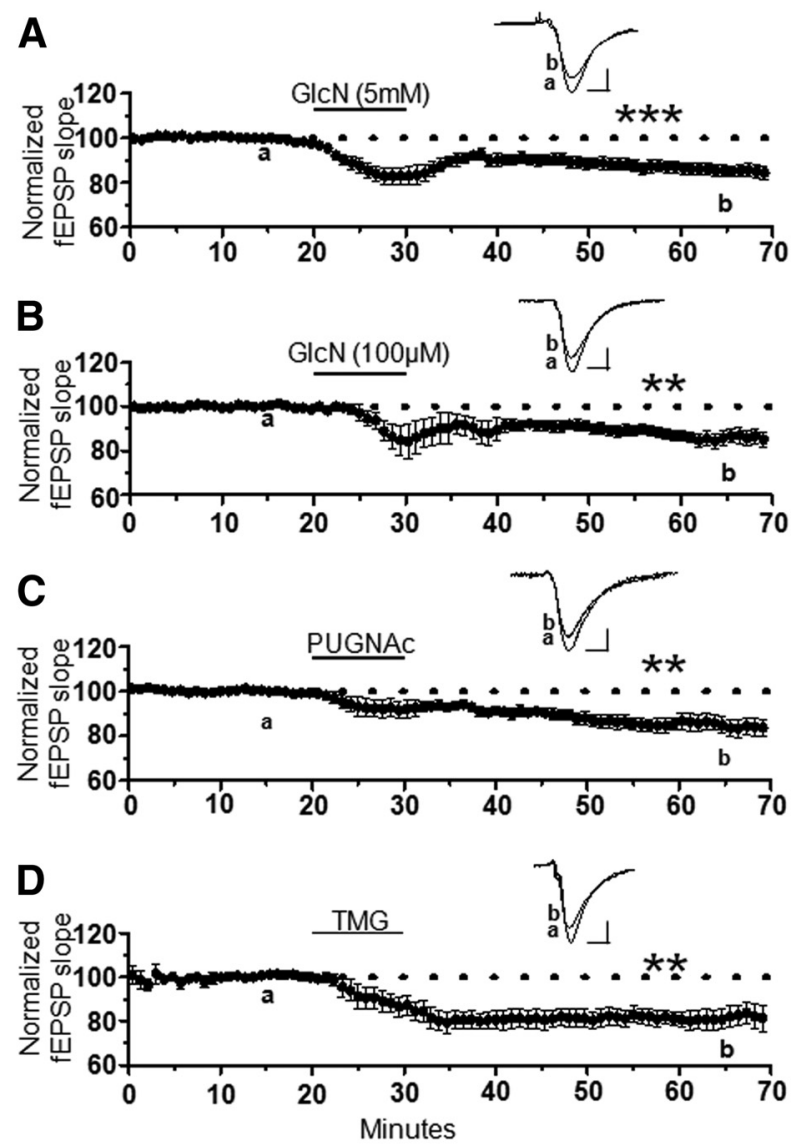

E

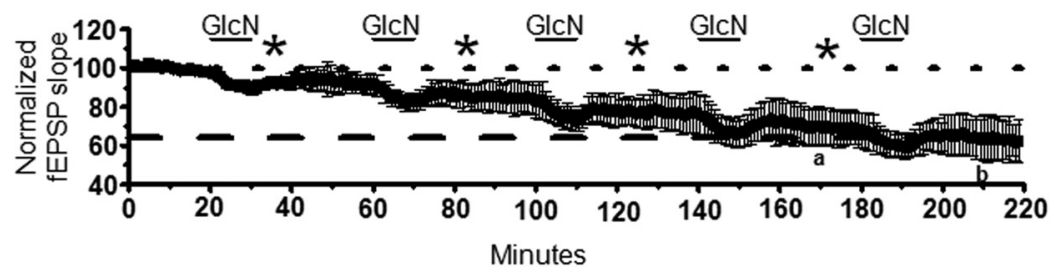

Figure 4. Increasing 0-GICNAcylation induces long-term synaptic depression at CA3-CA1 synapses. $A, B$, Glucosamine application (GlcN, $10 \mathrm{~min})$ at $(\boldsymbol{A}) 5 \mathrm{~mm}(n=11)$ or $(\boldsymbol{B}) 100 \mu \mathrm{m}(n=6)$ induces synaptic depression in extracellular dendritic field potential recordings at CA3-CA1 synapses in acutely to prepared hippocampal slices. C, D, Pharmacological blockade of 0 -GICNAcase (10 min) using (C) PUGNAc (30 $\mu \mathrm{m}, n=9)$ or (D) TMG $(1 \mu \mathrm{m}, n=6)$ induces synaptic depression. $\boldsymbol{E}$, Repeated GICN $5 \mathrm{~mm}$ application saturates the synaptic depression $(n=4) .{ }^{*} p<0.05,{ }^{* *} p<0.001$, and ${ }^{* * *} p<0.0001$. Error bars indicate SEM. Calibration: $0.4 \mathrm{mV}, 10 \mathrm{~ms}$.

O-GlcNAc LTD is not due to increased GABA $\mathrm{A}$-mediated inhibition or decreased presynaptic glutamate release, and is not NMDAR dependent

To determine whether an increase in GABAergic inhibition indirectly mediates $\mathrm{O}$-GlcNAc LTD, we applied glucosamine in the presence or absence of the $\mathrm{GABA}_{\mathrm{A}} \mathrm{R}$ antagonist picrotoxin. In interleaved experiments, there was a slight but significant increase in the magnitude of O-GlcNAc LTD in picrotoxin (GlcN: $88 \pm 3 \%$ of baseline fEPSP slope vs GlcN + picrotoxin: $75 \pm 6 \%$ of baseline fEPSP slope; $p<0.05$ ) clearly demonstrating that O-GlcNAc LTD is not a consequence of increased inhibitory transmission (Fig. 5A).

We next determined whether O-GlcNAc LTD results from decreased presynaptic release probability by analyzing the paired-pulse ratio (PPR), an indirect measure of presynaptic function (Dobrunz and Stevens, 1997). No significant difference was observed in PPR when comparing the ratio before and after glucosamine application (data not shown; 5 mu before: $1.4 \pm 0.1$ vs after: $1.4 \pm 0.1 ; p>$ $0.05 ; 100 \mu \mathrm{M}$ before: $1.5 \pm 0.1$ vs after: $1.5 \pm$ $0.1 ; p>0.05)$, suggesting that increased O-GlcNAc levels does not decrease glutamate release.

Because many forms of learning and memory-related plasticity are NMDARdependent, we determined whether OGlcNAc LTD shared this requirement. Slices were treated with either PUGNAc (Fig. $5 B$ ) or thiamet-G (Fig. $5 C$ ) in the presence (PUGNAc: $83 \pm 2 \%$ of baseline fEPSP slope $p<0.05$, TMG: $84 \pm 7 \%$ of baseline fEPSP slope; $p<0.05$ ) or absence (PUGNAc: $87 \pm 4 \%$ of baseline fEPSP slope, $p<0.05$; TMG: $82 \pm 3 \%$ of baseline fEPSP slope; $p<0.05)$ of DL-APV (100 $\mu \mathrm{M})$, an NMDAR antagonist. In interleaved experiments, NMDAR blockade did not affect the magnitude of O-GlcNAc LTD $(p>0.05$ for each treatment group in the presence and absence of APV), indicating that this plasticity is not NMDAR dependent.

\section{Increased protein O-GlcNAcylation impairs expression of \\ NMDAR-dependent LTP}

We next tested whether O-GlcNAc LTD interferes with induction of NMDARdependent LTP. High-frequency tetanus (HFS, $100 \mathrm{~Hz}, 0.5 \mathrm{~s}$ duration, $4 \times, 20 \mathrm{~s}$ intervals) was delivered following a 10 min glucosamine application to assess whether NMDAR-dependent LTP could be induced. It is important to note that the stimulus intensity was not increased to reestablish the original baseline following glucosamine application before delivering HFS to better mimic what might occur in vivo when $\mathrm{O}-\mathrm{GlcNAc}$ levels increase just before activity that should induce potentiation. In interleaved experiments, glucosamine application lead to decrementing LTP (116 $\pm 6 \%$ of baseline fEPSP slope; $p<0.05)$ compared with stable potentiation induced in the absence of glucosamine (136 $\pm 7 \%$ of baseline; $p<0.05$; Fig. $6 A 1)$.

Next, to test the effect of a more sustained increase in protein O-GlcNAcylation on LTP, slices were incubated in thiamet-G for $1 \mathrm{~h}$ and then were subjected to HFS to induce LTP. Both controltreated $(137 \pm 4 \%$ of baseline fEPSP slope; $p<0.001)$ and thiamet-G-treated ( $122 \pm 6 \%$ of baseline fEPSP slope; $p<0.05$ ) slices expressed significant LTP (Fig. 6A2); however, the magnitude of LTP was significantly decreased in the thiamet-G-treated slices compared with control ( $p<0.05$; Fig. 6A2). These findings suggest that increases in protein $\mathrm{O}-\mathrm{GlcNAcylation}$ interfere with the ability of synapses to express LTP.

To determine whether O-GlcNAc LTD is reversible, which is expected for a physiologically relevant plasticity, HFS was delivered during expression of O-GlcNAc LTD ( $92 \pm 1 \%$ of baseline fEPSP slope; $p<0.001$; Fig. $6 A 3$ ). Significant potentiation was 



Figure 5. $0-G I C N A C L T D$ is not due to an increase in $G_{A B A_{A}} R$-mediated transmission and is not NMDAR dependent. $A, G \mid c N(5 \mathrm{~mm}, 10 \mathrm{~min})$ induces LTD in the presence $(n=5)$ and absence $(n=6)$ of picrotoxin (4 mM). B, C, PUGNAC ( $30 \mu \mathrm{m}, 10 \mathrm{~min} ; \boldsymbol{B})$ or TMG $(\boldsymbol{C})$ induces LTD in the presence (PUGNAc: $n=4$, TMG: $n=7$ ) or absence (PUGNAc: $n=5$, TMG: $n=7$ ) of DL-APV (100 $\mu \mathrm{M}) .{ }^{*} p<0.05$. Error bars indicate SEM. Calibration: $0.4 \mathrm{mV}, 10 \mathrm{~ms}$.

observed relative to the original ( $107 \pm 2 \%$ of depressed baseline; $p<0.0 .0001)$ and depressed level of transmission $(115 \pm 2 \%$ of depressed baseline fEPSP slope; $p<0.05$ ), establishing that O-GlcNAc LTD is indeed reversible. However, even though LTP can be induced during O-GlcNAc LTD, the magnitude is less than that measured in an independent control set of experiments when HFS is delivered after acquiring a $50 \mathrm{~min}$ baseline (data not shown; control:133 $\pm 3 \%$ of baseline fEPSP slope vs during O-GlcNAc LTD reversal: $115 \pm 2 \%$ of baseline fEPSP slope; $p<0.05)$.

\section{Saturation of NMDAR-dependent LTD occludes O-GlcNAc LTD}

To determine whether O-GlcNAc LTD is additive with NMDARdependent LTD, we treated slices with glucosamine during LFS (1 $\mathrm{Hz}, 15 \mathrm{~min}$ ) to simultaneously induce O-GlcNAc LTD and NMDAR-dependent LTD. There was no significant difference in the magnitude of LTD measured in slices treated with glucosamine alone (Fig. 4A), LFS alone ( $89 \pm 5 \%$ of baseline fEPSP slope; Fig. $6 B 1)$, and LFS + glucosamine groups $(84 \pm 4 \%$ of baseline fEPSP slope; Fig. 6B1; one-way ANOVA $F_{(2,18)}=3.55$, $p=0.50$ ), suggesting that a shared mechanism underlies expression of the two plasticities. Of note is that LFS administered alone does not increase O-GlcNAcylation measured with immunoblot from isolated CA1 regions (data not shown; $n=6, p>0.05$ ). We next found that saturation of LTD with six rounds of LFS occludes thiamet-G-induced LTD (36 $\pm 5 \%$ of baseline fEPSP slope following sixth LFS application vs $35 \pm 7 \%$ of baseline fEPSP slope after TMG application, $p>0.05$; Fig. 6B2), further supporting the concept of a shared expression mechanism. Unexpectedly, when O-GlcNAc LTD was saturated using five rounds of glucosamine application, LFS induced further LTD ( $64 \pm 6 \%$ of baseline fEPSP slope following fifth GlcN application vs $53 \pm 6 \%$ of baseline fEPSP slope after LFS; $p<0.05$; Fig. 6B3).

\section{AMPAR subunit GluA2, but not GluA1, undergoes O-GlcNAc modification}

During expression of NMDAR-dependent LTP and LTD, serine phosphorylation/dephosphorylation regulates AMPAR trafficking. Because protein O-GlcNAcylation also occurs on serine residues, we investigated whether GluA1 and/or GluA2 AMPAR subunits undergo O-GlcNAcylation. Using immunoprecipitation techniques, we found that GluA2, but not GluA1, is O-GlcNAcylated under basal conditions (Fig. 7A), and that the same glucosamine treatment that induces LTD in electrophysiology studies significantly increases GluA2 O-GlcNAc levels. Moreover, OGT, the enzyme that catalyzes the attachment of O-GlcNAc to serine/threonine residues, coimmunoprecipitates with GluA2, but not GluA1, thereby providing further support for the notion that GluA2 is a substrate for OGT (Fig. 7A1,A2).

Phosphorylation of GluA2 serine 880 (Ser880) by PKC stimulates AMPAR internalization during expression of NMDARdependent LTD (Chung et al., 2000). Because O-GlcNAc LTD and NMDAR-dependent LTD appear to have a common expression mechanism based upon the data above, we examined whether increasing O-GlcNAcylation modulates Ser880 phosphorylation as an indicator of same-site modulation by O-GlcNAc and phosphorylation. Using synaptosomes, we found no change in Ser880 phosphorylation in the presence of thiamet-G (Fig. 7B), suggesting that O-GlcNAc LTD is not caused by modulation of Ser880 and that it is likely not PKC dependent. To confirm this, slices were treated with thiamet-G in the presence or absence of bisindolylmaleimide I (Bis I), a PKC inhibitor. Bis I had no effect on the magnitude of O-GlcNAc LTD (TMG: $80 \pm 6 \%$ of baseline fEPSP slope vs TMG + Bis I: $83 \pm 2 \%$ of baseline fEPSPS slope, $p>0.05$; Fig. 7C1), but as expected, NMDAR-dependent LTD was completely blocked (LFS: $76 \pm 4 \%$ of baseline fEPSP slope vs LFS + Bis I: $97 \pm 5 \%$ of baseline; $p<$ 0.05; Fig. 7C2).

In an effort to link O-GlcNAcylation of GluA2 with O-GlcNAc LTD, we investigated whether O-GlcNAc LTD can be induced in GluA2 knock-out (KO) mice. Note, even though Ser880 phosphorylation of GluA2 subunits is required for AMPAR internalization during NMDAR-dependent LTD (Chung et al., 2000; Kim et al., 2001), GluA2 KO mice have normal NMDAR-dependent LTP and LTD at CA3-CA1 synapses (Jia et al., 1996), likely due to dephosphorylation of GluA1, which also drives AMPAR endocytosis (Man et al., 2007). We show in slices from wild-type (WT) mice that thiamet-G application induces O-GlcNAc LTD, similar to our findings in rats $(85 \pm 2 \%$ of baseline fEPSP slope; $p<0.0001$; Fig. 7D1). In contrast, $\mathrm{O}-\mathrm{GlcNAc}$ LTD is completely absent in slices from GluA2 KO mice (106 $\pm 4 \%$ of baseline fEPSP slope, $p>0.05$; Fig. $7 D 1$ ), consistent with the interpretation that O-GlcNAc modification of GluA2 is causal to the expression of O-GlcNAc LTD. Immunoblot analysis from a subset of $\mathrm{KO}$ mice demonstrates absence of GluA2 expression (Fig. 7D2).

\section{Increased protein O-GlcNAcylation disrupts normal hippocampal-dependent learning}

We next pursued whether increased O-GlcNAcylation affects learning and memory using assays that require hippocampus. Rats were treated in vivo with thiamet-G (10 mg/kg, i.p.) or saline and hippocampal O-GlcNAc levels were assessed by immunoblot analysis. Thiamet-G-injected rats had increased hippocampal O-GlcNAc protein levels at $2 \mathrm{~h}$ (data not shown) through at least $8 \mathrm{~h}$ postinjection (Fig. $8 \mathrm{~A}$ ). Rats were first monitored in an open field to confirm that thiamet-G has no detrimental effects on 

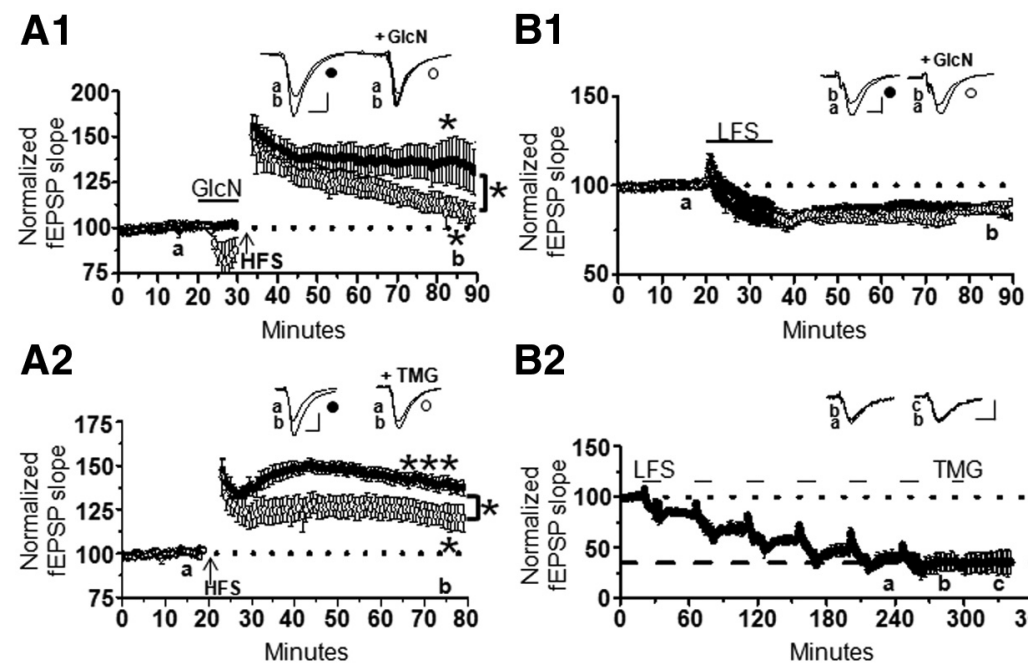

B2

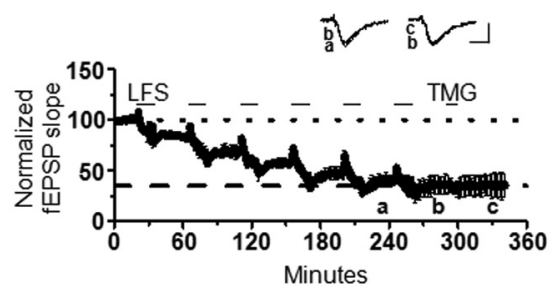

A3

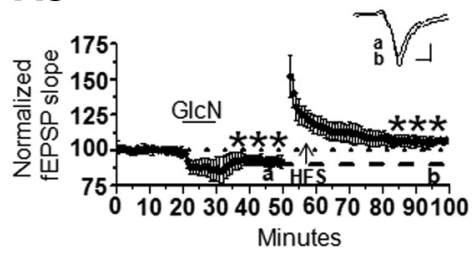

B3

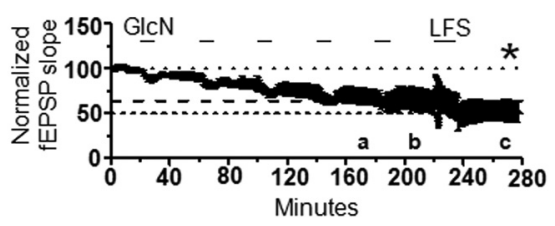

Figure 6. Interactions of protein 0-GICNAcylation with NMDAR-dependent LTP and LTD. A1, Decrementing LTP occurs when HFS is delivered immediately following a $10 \mathrm{~min} \mathrm{GICN}$ application ( $n=7$ with $100 \mu \mathrm{m} \mathrm{GlcN} ; n=6$ without GIcN). A2, Decreased LTP magnitude following $1 \mathrm{~h}$ treatment with TMG $(1 \mu \mathrm{M}, n=6$ with TMG; $n=6$ without TMG). A3, 0-GICNAc LTD is reversible using HFS to induce LTP $(n=6)$. B1, Simultaneous LFS and GIcN application (100 $\mu \mathrm{m}, 15 \mathrm{~min}, n=5)$ does not induce greater LTD than LFS alone $(n=5)$. B2, Saturation of NMDAR-dependent LTD occludes 0-GICNAc LTD $(n=3)$. B3, Saturation of 0-GIcNAc LTD does not occlude further LTD induced by LFS $(n=4) .{ }^{*} p<0.05,{ }^{* *} p<0.001$, and ${ }^{* * *} p<0.0001$. Error bars indicate SEM. Calibration: $0.4 \mathrm{mV}, 10 \mathrm{~ms}$.

mobility because skeletal muscle proteins can be O-GlcNAc modified (Hedou et al., 2007). Rats were tested in the open field at 2 and $4 \mathrm{~h}$ post saline/thiamet-G injection. No differences between groups were observed, but exploration time (Fig. $8 D$ ) was markedly reduced at the $4 \mathrm{~h}$ versus $2 \mathrm{~h}$ postinjection time point (Vehicle: 2 h:2881.69 $\pm 138.66,4$ h: $2081.24 \pm 243.53$; TMG: 2 h: $2830.48 \pm 169.64,4$ h: $2037.08 \pm 151.19$; one-way repeated measures (time) ANOVA $F_{(1,18)}=8.16, p<0.05$; Fig. $8 D$ ), likely due to decreased novelty of the environment. There was also no difference in the amount of time spent in the center between animal groups (data not shown; Vehicle: $2.1 \pm 0.9 \%$ time in center vs TMG: $2.1 \pm 0.9 \%$ time in center, $p>0.05)$ indicating no difference in anxiety levels.

For the NOR task, training was performed $2 \mathrm{~h}$ post vehicle or thiamet- $\mathrm{G}$ injection and rats were tested $2 \mathrm{~h}$ later for their ability to discriminate between novel and familiar objects. Importantly, before performing the NOR and NOP assays, side and object preference were ruled out (data not shown). No difference was observed in object exploration time during training (Vehicle: $17.9 \pm 3.7$ s, TMG: $18.8 \pm 3.5 \mathrm{~s}, p>0.05$; Fig. $8 B 1$ ). While the vehicle group demonstrates significant NOR compared with chance ( $66 \pm 4 \%$ time spent with the novel object; $p<0.05$ ), the thiamet-G-treated group did not distinguish between novel and familiar objects, spending equivalent time with the two objects that was not different from chance ( $56 \pm 5 \%$ time spent with the novel object, $p>0.05$; Fig. $8 B 2$ ). Importantly, because the vehicle- and thiamet-G-treated groups spent similar time initially exploring the objects during training (Fig. 8B1), the failure of
thiamet-G-treated animals to differentiate between novel and familiar objects is not due to decreased object exposure. In addition, there was no significant difference in the amount of time spent exploring the objects during testing (data not shown, Vehicle $16.7 \pm 2.2 \mathrm{~s}$ vs TMG $15.7 \pm 3.7 \mathrm{~s}, p>0.05)$. Furthermore, this lack of NOR in the thiamet-G-treated group but significant NOR in vehicletreated animals was confirmed in a second, completely separate cohort (data not shown; Vehicle: $71 \pm 5 \%$ time with the novel object, $n=9, p<0.05$; TMG $49 \pm 6 \%$ time with the novel object; $n=12, p>0.05)$, demonstrating that this behavioral deficit is robust and reproducible.

We next asked whether increasing O-GlcNAcylation induces a deficit in another task that requires hippocampal function, NOP. As before, no difference was observed in object exploration time during training (Vehicle: $15.2 \pm 2.2 \mathrm{~s}$ vs TMG: $14.9 \pm 2.9 \mathrm{~s}, p>0.05$; Fig. $8 C 1)$ or testing (data not shown; Vehicle: $12.4 \pm$ 1.9 s vs TMG: $21.7 \pm 4.9, p=0.11)$. However, similar to the results from NOR, the vehicle group demonstrates significant NOP compared with chance $(70 \pm 7 \%$ time spent in novel location; $p<0.05$ ) while the thiamet-G-treated group did not distinguish between novel and familiar locations, spending equivalent amounts of time investigating objects in both locations that were not different from chance ( $47 \pm 6 \%$ time spent in the novel location, $p>0.05$; Fig. $8 C 2$ ).

In contrast to the NOR and NOP deficits, we found no difference in freezing time between the vehicle- and thiamet-G-treated groups in CFC, another hippocampal-dependent behavior (Vehicle: $49 \pm 8 \%$ freezing, TMG: $53 \pm 5 \%$ freezing; one-way ANOVA $F_{(3,47)}=9.25, p<0.0001$; Fig. $\left.8 E\right)$, indicating that deficits do not generalize to all hippocampal-dependent learning tasks.

\section{Discussion}

Despite increasing recognition that synaptic proteins are targets for O-GlcNAc modification, remarkably little is known about the role of O-GlcNAcylation in synaptic function. Here we report a novel form of LTD at CA3-CA1 hippocampal synapses induced by acutely increasing $\mathrm{O}-$ GlcNAcylation that is NMDAR and PKC independent. We find that GluA2, but not GluA1, AMPAR subunits are O-GlcNAc modified and that O-GlcNAc LTD is absent in GluA2 KO mice, providing a mechanistic link between GluA2 O-GlcNAcylation and O-GlcNAc-LTD. Importantly, increasing O-GlcNAcylation in vivo interferes with novel object recognition and placement while CFC is intact. Collectively, these findings support the concept that acute changes in O-GlcNAcylation of synaptic proteins are a novel mechanism capable of modulating synaptic efficacy as well as memory processing.

Depression of baseline transmission occurring within minutes following application of glucosamine or O-GlcNAcase inhibitors provides strong support that cycling of O-GlcNAc on 
hippocampal synaptic proteins is highly dynamic. Our findings predict that, dependent upon availability of substrate and enzyme activity, cycling between increased and decreased O-GlcNAcylation can regulate basal synaptic strength on a moment-to-moment basis. Moreover, this process can control the ability of synapses to undergo long-term changes in synaptic efficacy, mechanisms that contribute to memory formation. The duration of the glucosamine-induced synaptic depression outlasts the transient increase in O-GlcNAcylation, suggesting that increased O-GlcNAcylation triggers the plasticity, rather than synaptic depression being a consequence of prolonged increase in O-GlcNAc levels. Furthermore, the finding that glucosamine and $\mathrm{O}$ GlcNAcase inhibition induce LTD of the same magnitude indicates that the same mechanism underlies LTD induction/expression, regardless of how $\mathrm{O}-$ GlcNAcylation is increased. Moreover, the fact that increasing O-GlcNAc synthesis or inhibiting O-GlcNAc degradation results in LTD of the same magnitude strongly supports the notion that it is the increase in O-GlcNAcylation that modulates synaptic function. While demonstrating that OGT inhibition blocks the effects of glucosamine would further substantiate these findings, no such validated specific OGT inhibitor is currently available.

The fact that O-GlcNAc LTD is both saturable and reversible is important in establishing it as a physiologically relevant process. Because O-GlcNAc LTD is neither NMDAR nor PKC dependent, its induction requirements are not shared with NMDARLTD. However, the lack of significant difference in LTD magnitude induced with glucosamine, LFS, and LFS + glucosamine suggests a possible shared expression mechanism. Furthermore, occlusion of O-GlcNAc LTD by prior saturation of NMDAR-dependent LTD supports this interpretation. Unfortunately, this interpretation is complicated by the lack of occlusion of NMDAR-dependent LTD following saturation of O-GlcNAc LTD using glucosamine. A possible explanation is desensitization or saturation of OGT, which limits full activation of induction mechanisms, thereby preventing complete saturation of O-GlcNAc LTD expression mechanisms. This concept is consistent with greater synaptic depression achieved at saturation with LFS versus repeated glucosamine application. Currently, it is not known in any system how OGT responds to repeated applications of glucosamine.

Increasing O-GlcNAc levels increases GluA2 O-GlcNAcylation without affecting GluA2 Ser880 phosphorylation suggesting that PKC-dependent phosphorylation of GluA2 Ser880 and O-GlcNAc modification of some other serine/threonine residue(s) represent different mechanisms available to modulate AMPAR function. Identifying which GluA2 serine/threonine residue(s) are O-GlcNAcylated, and whether this stimulates a PICK1-dependent endocytosis mechanism similar to the PKC-dependent phosphorylation of GluA2 (McDonald et al., 2001; Seidenman et al., 2003), remains to be determined. Alternatively, O-GlcNAc-LTD could require Arc-mediated endocytosis as in mGluR-LTD (Waung et al., 2008). Currently it is also not known whether PICK1, Arc, or other scaffolding proteins involved in AMPAR trafficking are O-GlcNAc modified and how this might modulate interaction with AMPARs when GluA2 is O-GlcNAcylated. Clearly, much more work in this area is necessary.

A role for O-GlcNAcylation of GluA2 in O-GlcNAc LTD was substantiated using GluA2 KO mice where NMDAR-LTD is normal (Jia et al., 1996), likely because AMPAR internalization mediated by dephosphorylation of GluA1 Ser845 compensates for the lack of GluA2 (Mulkey et al., 1994; Chung et al., 2000; Morishita et al., 2005; Man et al., 2007). The preservation of NMDARdependent LTD but clear absence of O-GlcNAc-LTD in GluA2 $\mathrm{KO}$ mice, combined with the lack of O-GlcNAcylation of GluA1, provides strong evidence for a mechanistic link between GluA2 O-GlcNAcylation and expression of O-GlcNAc-LTD.

Because LTD at hippocampal synapses is induced during some forms of hippocampal learning (Manahan-Vaughan and Braunewell, 1999; Kemp and Manahan-Vaughan, 2004, 2012), it cannot be concluded that O-GlcNAc-LTD causes behavioral deficits. Although the physiological role of O-GlcNAcylation on synaptic function is unknown, the fact that increasing O-GlcNAc levels caused a deficit in NOR and NOP demonstrates the potential role for O-GlcNAcylation in regulating cognitive function in 

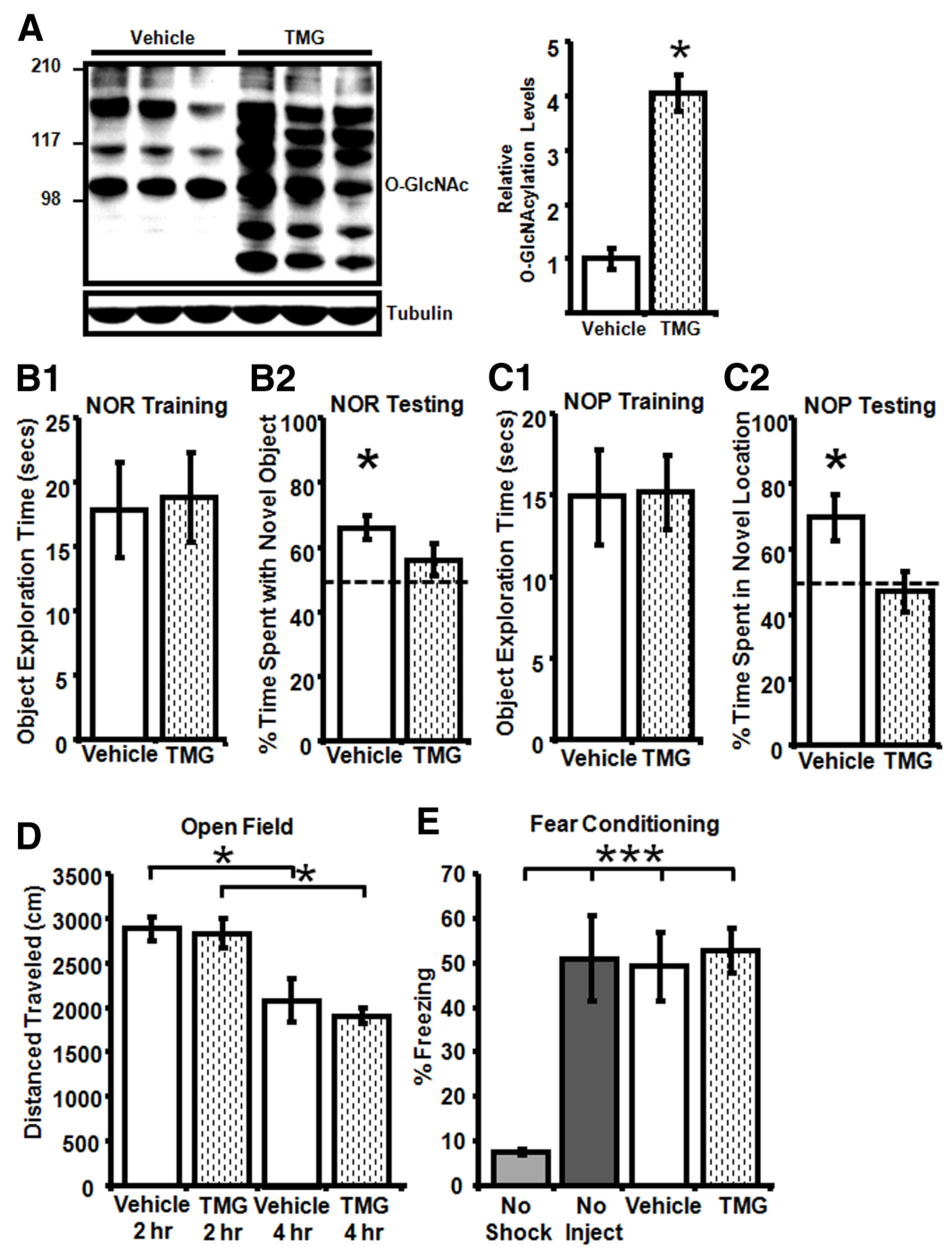

Figure 8. Increased protein 0-GICNAcylation impairs NOR but has no effect on CFC. $A$, In vivo TMG treatment ( $10 \mathrm{mg} / \mathrm{kg}$, i.p.) increases 0 -GICNAcylation in hippocampus measured $8 \mathrm{~h}$ post injection $(n=7)$. $\boldsymbol{B}$, № difference in object exploration time between Vehicle-treated $(n=6)$ and TMG-treated $(n=9)$ rats during training. B2, During testing, TMG-treated rats $(n=9)$ do not spend more time than chance with the novel versus familiar object, while Vehicle-treated rats $(n=6)$ spend significantly more time with the novel object. C1, No difference in object exploration time between Vehicle-treated $(n=9)$ and TMG-treated $(n=$ 9) rats during training. (2, During testing, TMG-treated rats $(n=9)$ do not spend more time than chance investigating the object in the familiar versus novel location, while Vehicle-treated rats $(n=9)$ spend significantly more time investigating the object in the novel location. $\boldsymbol{D}$, No group differences in locomotor activity during open field testing 2 and $4 \mathrm{~h}$ post injection in Vehicle-treated $(n=9)$ and TMG-treated $(n=10)$ rats. One-way repeated-measures ANOVA with Tukey's post hoc analysis. $\boldsymbol{E}$, No significant difference in time spent freezing between Vehicle-treated $(n=17)$ and TMG-treated rats $(n=15)$ in CFC. One-way ANOVA with Tukey's post hoc; ${ }^{*} p<0.05$ and ${ }^{* * *} p<0.0001$. Error bars indicate SEM.

vivo. Because strong postsynaptic depolarization is required during induction of NMDAR-dependent LTP, O-GlcNAc-LTD could serve as a "break" on LTP induction, and prevent hyperexcitability, where enhanced glutamatergic transmission could be detrimental to neuronal survival. On the other hand, inhibition of LTP under conditions of chronically elevated O-GlcNAc, such as in diabetes (Liu et al., 2004), could lead to cognitive deficits, consistent with deficits observed in NOR and NOP. Importantly, the deficits in NOR and NOP but not in CFC suggest that not all forms of hippocampal-dependent learning and memory are similarly regulated by O-GlcNAcylation. Although all tasks used are hippocampal dependent, they require other brain regions, which could explain the lack of deficit in CFC compared with NOR and NOP. The deficit in NOR and NOP measured $2 \mathrm{~h}$ post-training indicates impaired short-term memory. Because animals were treated with thiamet-G before training, additional studies are needed to determine whether increased O-GlcNAcylation impairs acquisition versus retrieval. Interestingly, a mouse model of Fragile X mental retardation also exhibits a selective deficit in NOR while CFC remains normal, similar to our findings here (Ventura et al., 2004; Thomas et al., 2012). It is important to note that because thiamet-G was administered systemically, an increase in O-GlcNAcylation in other brain regions may contribute to the observed deficits in NOR and NOP. More work is clearly needed to fully explore how protein O-GlcNAcylation modifies function of particular neuronal circuits and proteins that underlie memory processing.

To date, only two other studies have examined the role of O-GlcNAcylation on hippocampal synaptic function (Tallent et al., 2009; Kanno et al., 2010). Unfortunately, these studies reported contradictory findings, which are also inconsistent with our observations. Tallent et al. (2009) reported no effect on basal hippocampal synaptic transmission and enhanced LTP at CA3-CA1 synapses assessed in slices $4-5 \mathrm{~h}$ following in vivo administration of an O-GlcNAcase inhibitor. The systemic in vivo versus in vitro treatment with the O-GlcNAcase inhibitor and differences in timing of the studies after treatment ( $1 \mathrm{~h}$ vs $4-5 \mathrm{~h}$ ) may account for the differences because $\mathrm{O}$ GlcNAc modification likely changes with time after O-GlcNAcase inhibition. Kanno et al. (2010) reported that in vitro treatment of hippocampal slices with alloxan, a putative OGT inhibitor (Lee et al., 2006), increased the LTP magnitude at CA3-CA1 synapses, but Tallent et al. (2009) observed a decrease in LTP following in vivo alloxan administration. Importantly, while alloxan has been used as an OGT inhibitor, it is only effective at high concentrations, lacks specificity (Tiedge et al., 2000), and also inhibits O-GlcNAcase (Lee et al., 2006). Therefore, because of off-target effects and because changes in O-GlcNAc levels were not reported by Kanno et al. (2010), it is difficult to draw meaningful conclusions. Recently, it has been shown that Ser40 on CREB is highly O-GlcNAcylated under basal conditions and is increased by activity, and requires phosphorylation at Ser133. Whereas phosphorylation of Ser133 increases CREB-mediated transcription in neurons during memory formation (Deisseroth et al., 1998), increasing O-GlcNAc on CREB Ser40 inhibits both basal and activity-induced CREB-mediated transcription and causes impairment in memory consolidation (Rexach et al., 2012). Whether CREB Ser40 is O-GlcNAc modified following in 
vivo thiamet-G treatment is not yet known, but is an important next step.

Mounting evidence shows a causal relationship between perturbations in O-GlcNAcylation and heart disease, cancer, $\mathrm{AD}$, and diabetes (Chou et al., 1995; Love and Hanover, 2005; Liu et al., 2006; Dias and Hart, 2007; Fülöp et al., 2008), although the cellular mechanisms are far from understood. In contrast, recent studies suggest O-GlcNAcylation may be an endogenous, rapidly activated stress survival response (Zachara et al., 2004; Liu et al., 2006). For example, increasing O-GlcNAcylation is protective in AD mouse models whereby O-GlcNAcylation of Tau Ser400 decreases phosphorylation of pathological neighboring serines (Smet-Nocca et al., 2011; Yuzwa et al., 2012). Thus, while the role of O-GlcNAcylation in modulating cellular function is multifaceted and complex, it clearly mediates normal physiological cellular responses and pathophysiological changes when dysregulated.

In conclusion, our results strengthen the concept that O-GlcNAc modification of synaptic proteins in hippocampal neurons plays a central role in the dynamic molecular regulation of synaptic efficacy, mechanisms believed to contribute to learning and memory. Modulation of O-GlcNAc levels occur within a timescale of minutes supporting the underlying premise that protein O-GlcNAcylation is a dynamically active process that can directly regulate normal physiological function and it could be an important target for treatment of neurological disease.

\section{References}

Akimoto Y, Comer FI, Cole RN, Kudo A, Kawakami H, Hirano H, Hart GW (2003) Localization of the O-GlcNAc transferase and O-GlcNAcmodified proteins in rat cerebellar cortex. Brain Res 966:194-205. CrossRef Medline

Bliss TV, Lomo T (1973) Long-lasting potentiation of synaptic transmission in the dentate area of the anaesthetized rabbit following stimulation of the perforant path. J Physiol 232:331-356. Medline

Chou TY, Dang CV, Hart GW (1995) Glycosylation of the c-Myc transactivation domain. Proc Natl Acad Sci U S A 92:4417-4421. CrossRef Medline

Chung HJ, Xia J, Scannevin RH, Zhang X, Huganir RL (2000) Phosphorylation of the AMPA receptor subunit GluR2 differentially regulates its interaction with PDZ domain-containing proteins. J Neurosci 20:72587267. Medline

Cole RN, Hart GW (2001) Cytosolic O-glycosylation is abundant in nerve terminals. J Neurochem 79:1080-1089. Medline

Deisseroth K, Heist EK, Tsien RW (1998) Translocation of calmodulin to the nucleus supports CREB phosphorylation in hippocampal neurons. Nature 392:198-202. CrossRef Medline

Deng Y, Li B, Liu Y, Iqbal K, Grundke-Iqbal I, Gong CX (2009) Dysregulation of insulin signaling, glucose transporters, O-GlcNAcylation, and phosphorylation of tau and neurofilaments in the brain: implication for Alzheimer's disease. Am J Pathol 175:2089-2098. CrossRef Medline

Dias WB, Hart GW (2007) O-GlcNAc modification in diabetes and Alzheimer's disease. Mol Biosyst 3:766-772. CrossRef Medline

Dobrunz LE, Stevens CF (1997) Heterogeneity of release probability, facilitation, and depletion at central synapses. Neuron 18:995-1008. CrossRef Medline

Dudek SM, Bear MF (1992) Homosynaptic long-term depression in area CA1 of hippocampus and effects of N-methyl-D-aspartate receptor blockade. Proc Natl Acad Sci U S A 89:4363-4367. CrossRef Medline

Fülöp N, Mason MM, Dutta K, Wang P, Davidoff AJ, Marchase RB, Chatham JC (2007) Impact of Type 2 diabetes and aging on cardiomyocyte function and O-linked $\mathrm{N}$-acetylglucosamine levels in the heart. Am J Physiol Cell Physiol 292:C1370-1378. Medline

Fülöp N, Feng W, Xing D, He K, Not LG, Brocks CA, Marchase RB, Miller AP, Chatham JC (2008) Aging leads to increased levels of protein O-linked $\mathrm{N}$-acetylglucosamine in heart, aorta, brain and skeletal muscle in BrownNorway rats. Biogerontology 9:139-151. CrossRef Medline

Gupta S, Kim SY, Artis S, Molfese DL, Schumacher A, Sweatt JD, Paylor RE, Lubin FD (2010) Histone methylation regulates memory formation. J Neurosci 30:3589-3599. CrossRef Medline
Han I, Kudlow JE (1997) Reduced O glycosylation of Sp1 is associated with increased proteasome susceptibility. Mol Cell Biol 17:2550-2558. Medline

Hedou J, Cieniewski-Bernard C, Leroy Y, Michalski JC, Mounier Y, Bastide B (2007) O-linked N-acetylglucosaminylation is involved in the Ca2+ activation properties of rat skeletal muscle. J Biol Chem 282:10360-10369. CrossRef Medline

Hulette CM, Welsh-Bohmer KA, Crain B, Szymanski MH, Sinclaire NO, Roses AD (1997) Rapid brain autopsy. The Joseph and Kathleen Bryan Alzheimer's Disease Research Center experience. Arch Pathol Lab Med 121:615-618. Medline

Jia Z, Agopyan N, Miu P, Xiong Z, Henderson J, Gerlai R, Taverna FA, Velumian A, MacDonald J, Carlen P, Abramow-Newerly W, Roder J (1996) Enhanced LTP in mice deficient in the AMPA receptor GluR2. Neuron 17:945-956. CrossRef Medline

Kanno T, Yaguchi T, Nagata T, Mukasa T, Nishizaki T (2010) Regulation of AMPA receptor trafficking by O-glycosylation. Neurochem Res 35:782788. CrossRef Medline

Kemp A, Manahan-Vaughan D (2004) Hippocampal long-term depression and long-term potentiation encode different aspects of novelty acquisition. Proc Natl Acad Sci U S A 101:8192-8197. CrossRef Medline

Kemp A, Manahan-Vaughan D (2012) Passive spatial perception facilitates the expression of persistent hippocampal long-term depression. Cereb Cortex 22:1614-1621. CrossRef Medline

Khidekel N, Arndt S, Lamarre-Vincent N, Lippert A, Poulin-Kerstien KG, Ramakrishnan B, Qasba PK, Hsieh-Wilson LC (2003) A chemoenzymatic approach toward the rapid and sensitive detection of O-GlcNAc posttranslational modifications. J Am Chem Soc 125:16162-16163. CrossRef Medline

Khidekel N, Ficarro SB, Peters EC, Hsieh-Wilson LC (2004) Exploring the O-GlcNAc proteome: direct identification of O-GlcNAc-modified proteins from the brain. Proc Natl Acad Sci U S A 101:13132-13137. CrossRef Medline

Khidekel N, Ficarro SB, Clark PM, Bryan MC, Swaney DL, Rexach JE, Sun YE, Coon JJ, Peters EC, Hsieh-Wilson LC (2007) Probing the dynamics of $\mathrm{O}-\mathrm{GlcNAc}$ glycosylation in the brain using quantitative proteomics. Nat Chem Biol 3:339-348. CrossRef Medline

Kim CH, Chung HJ, Lee HK, Huganir RL (2001) Interaction of the AMPA receptor subunit GluR2/3 with PDZ domains regulates hippocampal long-term depression. Proc Natl Acad Sci U S A 98:11725-11730. CrossRef Medline

Kneass ZT, Marchase RB (2004) Neutrophils exhibit rapid agonist-induced increases in protein-associated O-GlcNAc. J Biol Chem 279:4575945765. CrossRef Medline

Laczy B, Fülöp N, Onay-Besikci A, Des Rosiers C, Chatham JC (2011) Acute regulation of cardiac metabolism by the hexosamine biosynthesis pathway and protein O-GlcNAcylation. PLoS One 6:e18417. CrossRef Medline

Lee HK, Barbarosie M, Kameyama K, Bear MF, Huganir RL (2000) Regulation of distinct AMPA receptor phosphorylation sites during bidirectional synaptic plasticity. Nature 405:955-959. CrossRef Medline

Lee HK, Takamiya K, Han JS, Man H, Kim CH, Rumbaugh G, Yu S, Ding L, He C, Petralia RS, Wenthold RJ, Gallagher M, Huganir RL (2003) Phosphorylation of the AMPA receptor GluR1 subunit is required for synaptic plasticity and retention of spatial memory. Cell 112:631-643. CrossRef Medline

Lee TN, Alborn WE, Knierman MD, Konrad RJ (2006) Alloxan is an inhibitor of O-GlcNAc-selective N-acetyl-beta-D-glucosaminidase. Biochem Biophys Res Commun 350:1038-1043. CrossRef Medline

Liu J, Pang Y, Chang T, Bounelis P, Chatham JC, Marchase RB (2006) Increased hexosamine biosynthesis and protein O-GlcNAc levels associated with myocardial protection against calcium paradox and ischemia. J Mol Cell Cardiol 40:303-312. CrossRef Medline

Liu K, Paterson AJ, Zhang F, McAndrew J, Fukuchi K, Wyss JM, Peng L, Hu Y, Kudlow JE (2004) Accumulation of protein O-GlcNAc modification inhibits proteasomes in the brain and coincides with neuronal apoptosis in brain areas with high O-GlcNAc metabolism. J Neurochem 89:10441055. CrossRef Medline

Love DC, Hanover JA (2005) The hexosamine signaling pathway: deciphering the "O-GlcNAc code." Sci STKE 2005:re13. Medline

Malenka RC, Bear MF (2004) LTP and LTD: an embarrassment of riches. Neuron 44:5-21. CrossRef Medline 
Malinow R, Malenka RC (2002) AMPA receptor trafficking and synaptic plasticity. Annu Rev Neurosci 25:103-126. CrossRef Medline

Manahan-Vaughan D, Braunewell KH (1999) Novelty acquisition is associated with induction of hippocampal long-term depression. Proc Natl Acad Sci U S A 96:8739-8744. CrossRef Medline

Man HY, Sekine-Aizawa Y, Huganir RL (2007) Regulation of \{alpha\}amino-3-hydroxy-5-methyl-4-isoxazolepropionic acid receptor trafficking through PKA phosphorylation of the Glu receptor 1 subunit. Proc Natl Acad Sci U S A 104:3579-3584. CrossRef Medline

McCutchen E, Scheiderer CL, Dobrunz LE, McMahon LL (2006) Coexistence of muscarinic long-term depression with electrically induced longterm potentiation and depression at CA3-CA1 synapses. J Neurophysiol 96:3114-3121. CrossRef Medline

McDonald BJ, Chung HJ, Huganir RL (2001) Identification of protein kinase $\mathrm{C}$ phosphorylation sites within the AMPA receptor GluR2 subunit. Neuropharmacology 41:672-679. CrossRef Medline

Morishita W, Marie H, Malenka RC (2005) Distinct triggering and expression mechanisms underlie LTD of AMPA and NMDA synaptic responses. Nat Neurosci 8:1043-1050. CrossRef Medline

Mulkey RM, Endo S, Shenolikar S, Malenka RC (1994) Involvement of a calcineurin/inhibitor-1 phosphatase cascade in hippocampal long-term depression. Nature 369:486-488. CrossRef Medline

Rexach JE, Clark PM, Mason DE, Neve RL, Peters EC, Hsieh-Wilson LC (2012) Dynamic O-GlcNAc modification regulates CREB-mediated gene expression and memory formation. Nat Chem Biol 8:253-261. CrossRef Medline

Scheiderer CL, Smith CC, McCutchen E, McCoy PA, Thacker EE, Kolasa K, Dobrunz LE, McMahon LL (2008) Coactivation of M(1) muscarinic and alpha1 adrenergic receptors stimulates extracellular signal-regulated protein kinase and induces long-term depression at CA3-CA1 synapses in rat hippocampus. J Neurosci 28:5350-5358. CrossRef Medline

Seidenman KJ, Steinberg JP, Huganir R, Malinow R (2003) Glutamate receptor subunit 2 Serine 880 phosphorylation modulates synaptic transmission and mediates plasticity in CA1 pyramidal cells. J Neurosci 23: 9220-9228. Medline

Smet-Nocca C, Broncel M, Wieruszeski JM, Tokarski C, Hanoulle X, Leroy A, Landrieu I, Rolando C, Lippens G, Hackenberger CP (2011) Identification of O-GlcNAc sites within peptides of the Tau protein and their impact on phosphorylation. Mol Biosyst 7:1420-1429. CrossRef Medline

Smith CC, McMahon LL (2005) Estrogen-induced increase in the magnitude of long-term potentiation occurs only when the ratio of NMDA transmission to AMPA transmission is increased. J Neurosci 25:77807791. CrossRef Medline

Smith CC, McMahon LL (2006) Estradiol-induced increase in the magnitude of long-term potentiation is prevented by blocking NR2Bcontaining receptors. J Neurosci 26:8517-8522. CrossRef Medline
Stead JD, Clinton S, Neal C, Schneider J, Jama A, Miller S, Vazquez DM, Watson SJ, Akil H (2006) Selective breeding for divergence in noveltyseeking traits: heritability and enrichment in spontaneous anxiety-related behaviors. Behav Genet 36:697-712. CrossRef Medline

Tallent MK, Varghis N, Skorobogatko Y, Hernandez-Cuebas L, Whelan K, Vocadlo DJ, Vosseller K (2009) In vivo modulation of O-GlcNAc levels regulates hippocampal synaptic plasticity through interplay with phosphorylation. J Biol Chem 284:174-181. Medline

Thomas AM, Bui N, Perkins JR, Yuva-Paylor LA, Paylor R (2012) Group I metabotropic glutamate receptor antagonists alter select behaviors in a mouse model for fragile X syndrome. Psychopharmacology 219:47-58. CrossRef Medline

Tiedge M, Richter T, Lenzen S (2000) Importance of cysteine residues for the stability and catalytic activity of human pancreatic beta cell glucokinase. Arch Biochem Biophys 375:251-260. CrossRef Medline

Torres CR, Hart GW (1984) Topography and polypeptide distribution of terminal $\mathrm{N}$-acetylglucosamine residues on the surfaces of intact lymphocytes. Evidence for O-linked GlcNAc. J Biol Chem 259:3308-3317. Medline

Ventura R, Pascucci T, Catania MV, Musumeci SA, Puglisi-Allegra S (2004) Object recognition impairment in Fmrl knockout mice is reversed by amphetamine: involvement of dopamine in the medial prefrontal cortex. Behav Pharmacol 15:433-442. CrossRef Medline

Waung MW, Pfeiffer BE, Nosyreva ED, Ronesi JA, Huber KM (2008) Rapid translation of Arc/Arg3.1 selectively mediates mGluR-dependent LTD through persistent increases in AMPAR endocytosis rate. Neuron 59:8497. CrossRef Medline

Yuzwa SA, Vocadlo DJ (2009) O-GlcNAc modification and the tauopathies: insights from chemical biology. Curr Alzheimer Res 6:451-454. CrossRef Medline

Yuzwa SA, Macauley MS, Heinonen JE, Shan X, Dennis RJ, He Y, Whitworth GE, Stubbs KA, McEachern EJ, Davies GJ, Vocadlo DJ (2008) A potent mechanism-inspired O-GlcNAcase inhibitor that blocks phosphorylation of tau in vivo. Nat Chem Biol 4:483-490. CrossRef Medline

Yuzwa SA, Shan X, Macauley MS, Clark T, Skorobogatko Y, Vosseller K, Vocadlo DJ (2012) Increasing O-GlcNAc slows neurodegeneration and stabilizes tau against aggregation. Nat Chem Biol 8:393-399. CrossRef Medline

Zachara NE, O'Donnell N, Cheung WD, Mercer JJ, Marth JD, Hart GW (2004) Dynamic O-GlcNAc modification of nucleocytoplasmic proteins in response to stress. A survival response of mammalian cells. J Biol Chem 279:30133-30142. CrossRef Medline

Zou L, Zhu-Mauldin X, Marchase RB, Paterson AJ, Liu J, Yang Q, Chatham JC (2012) Glucose deprivation-induced increase in protein O-GlcNAcylation in cardiomyocytes is calcium-dependent. J Biol Chem 287:34419-34431. CrossRef Medline 